\title{
Low-frequency modulation and trend of the relationship between ENSO and precipitation along the northern to centre Peruvian Pacific coast
}

\author{
Luc Bourrel, ${ }^{1 *}$ Pedro Rau, ${ }^{1,4}$ Boris Dewitte, ${ }^{2}$ David Labat, ${ }^{1}$ Waldo Lavado, ${ }^{3}$ Aude Coutaud, ${ }^{1}$ \\ Andrea Vera, ${ }^{1}$ Abigail Alvarado ${ }^{1}$ and Julio Ordoñez ${ }^{3}$ \\ ${ }^{1}$ UMR 5563 GET, Université de Toulouse - CNRS - IRD - OMP - CNES, Toulouse 31400, France \\ ${ }^{2}$ UMR 5566 LEGOS, Université de Toulouse - CNRS - IRD - OMP - CNES, Toulouse 31400, France \\ ${ }^{3}$ SENAMHI, Lima 11, Peru \\ ${ }^{4}$ IMEFEN, Universidad Nacional de Ingeniería, Lima 25, Peru
}

\begin{abstract}
:
The relationship between El Niño Southern Oscillation (ENSO) and precipitation along the Peruvian Pacific coast is investigated over 1964-2011 on the basis of a variety of indices accounting for the different types of El Niño events and atmospheric and oceanographic manifestations of the interannual variability in the tropical Pacific. We show the existence of fluctuations in the ENSO/precipitation relationship at decadal timescales that are associated with the ENSO property changes over the recent decades. Several indices are considered in order to discriminate the influence of the two types of El Niño, namely, the eastern Pacific El Niño and the central Pacific El Niño, as well as the influence of large-scale atmospheric variability associated to the Madden and Julian Oscillation, and of regional oceanic conditions.

Three main periods are identified that correspond to the interleave periods between the main climatic transitions over 1964-2011, i.e. the shifts of the 1970s and the 2000s, over which ENSO experiences significant changes in its characteristics. We show that the relationship between ENSO and precipitation along the western coast of Peru has experienced significant decadal change. Whereas El Niño events before 2000 lead to increased precipitation, in the 2000s, ENSO is associated to drier conditions. This is due to the change in the main ENSO pattern after 2000 that is associated to cooler oceanic conditions off Peru during warm events (i.e. central Pacific El Niño). Our analysis also indicates that the two extreme El Niño events of 1982/1983 and 1997/1998 have overshadowed actual trends in the relationship between interannual variability in the tropical Pacific and precipitation along the coast of Peru. Overall, our study stresses on the complexity of the hydrological cycle on the western side of the Andes with regard to its relationship with the interannual to decadal variability in the tropical Pacific. Copyright @ 2014 John Wiley \& Sons, Ltd.
\end{abstract}

KEY WORDS precipitation; ENSO; Modoki; decadal modulation; trend; Pacific coast; Peru

Received 12 June 2013; Accepted 15 May 2014

\section{INTRODUCTION}

El Niño in Peru is often associated with heavy rain along the coastal fringe of the country due to the intrusion of warm tropical waters along the coast that allows deep convection in a region where cold upwelled waters and semi-arid to arid climate usually prevail (Tapley and Waylen, 1990; Lagos and Buizer, 1992). Over the last decades, two extreme El Niño events (1982/1983 and 1997/1998) took place that had large socio-economical consequences because of the disasters caused by the floods and droughts. According to OPS (2000), direct

*Correspondence to: Luc Bourrel, UMR 5563 GET, Université de Toulouse CNRS - IRD - OMP - CNES, 14 Avenue Edouard Belin, Toulouse 31400, France.

E-mail: bourrel@get.obs-mip.fr losses caused by the $1997 / 1998$ event was estimated at $\$ 1000 \mathrm{~m}$, of which $\$ 800 \mathrm{~m}$ were in the northern Pacific coast, as a result of heavy rains, and $\$ 200 \mathrm{~m}$ were in the southern Andes region, due to the effects of droughts. The economic impact of these disasters induced a $12 \%$ significant reduction of the GDP of Peru.

Considering the societal concern, recent studies have thus been devoted to inferring precipitation in Peru on the basis of seasonal forecast products from climate models (Lagos et al., 2008). The approach consists in building a statistical model between local precipitation as inferred from observations and climate indices as derived from sea surface temperature (SST) of the tropical Pacific predicted by the seasonal forecast systems (e.g. NCEP). Lagos et al. (2008) showed that this can provide a useful approach for predicting extreme events at least, although some indices (i.e. NINO1+2) may not be as reliable as others (i.e. 
NINO3.4, NINO4) for precipitation predictions in Peru. The skill of the forecast system is also highly dependent on the selected predictors and statistical method. For instance, the linear assumption, often used for the statistical approach, is certainly not the most appropriate for predicting precipitation in Peru, because El Niño Southern Oscillation (ENSO) has a strong positive asymmetry (evidenced by the extreme warm events) reflecting the nonlinearity in the system (An and Jin, 2004). Recent studies have revealed that there are also different types of El Niño events that have distinct characteristics in terms of atmospheric teleconnections (Yeh et al., 2009), frequency (Kim and Yu, 2012) and oceanographic manifestations off Peru (Dewitte et al., 2012). Two types of El Niño events have been documented so far in the literature (Ashok et al., 2007; Kug et al., 2009): the so-called Cold Tongue El Niño or eastern Pacific El Niño (hereafter EP El Niño) that corresponds to extreme warm events developing strong SST anomalies in the eastern equatorial Pacific and the Warm Pool El Niño or central Pacific El Niño (hereafter CP El Niño) that corresponds to standing warm SST anomaly development in the central equatorial Pacific, within the so-called Warm Pool region. In a recent study, Takahashi et al. (2011) suggest that the dominant mode of variability in the equatorial Pacific is in fact associated to a regime that encompasses the $\mathrm{CP}$ El Niño and that the EP El Niño events are extreme events, which are by definition much rarer than CP El Niño events. This view has of course implications for the study of the ENSO teleconnection pattern over Peru for precipitation because CP El Niño events are characterized by weak anomalous SST conditions off Peru compared with EP El Niño (Dewitte et al., 2012).

In addition, ENSO is a non-stationary phenomenon (Boucharel et al., 2009) having a significant modulation of its characteristics (amplitude, frequency and asymmetry) at decadal timescales (Guilderson and Schrag, 1998; Torrence and Compo, 1998). For instance, there has been a climate shift in the 1970s from when EP El Niño events became stronger (Miller et al., 1994). The 1980s and 1990s are in fact the decades over which the relationship between ENSO and hydrology (precipitations and discharges) in Peru (Lagos et al., 2008; Lavado et al., 2013), in Chile (Montecinos and Aceituno, 2003) and in Ecuador (Bourrel et al., 2010; 2011) is the most significant because of the strong signature on the regional circulation of the two extreme events of 1982/1983 and 1997/1998. Over the last two decades, the CP El Niño has however become more frequent relatively to the $\mathrm{EP} \mathrm{El}$ Niño (Yeh et al., 2009; Lee and McPhaden, 2010; Takahashi et al., 2011). Such change in the ENSO characteristics has been shown to modify features of the equatorial oceanic and atmospheric circulation in the
Pacific, i.e. the oceanic equatorial Kelvin waves (Dewitte et al., 2012) and the intraseasonal atmospheric variability (Gushchina and Dewitte, 2012) including the Madden and Julian Oscillation (MJO) (Madden and Julian, 1972).

All these aspects of the change in ENSO properties have been somewhat overlooked in studies addressing the impact of ENSO on the precipitations along the coast of Peru, although they can provide guidances for refining current forecasting strategies aimed at improving resource management (agriculture and water resources).

In this paper, our motivation is to revisit the relationship between ENSO and precipitations along the coast of Peru, taking into account different aspects of its manifestations on SST and in the atmosphere in the tropical Pacific, as well as its low-frequency property changes, in particular the increased occurrence of $\mathrm{CP} \mathrm{El}$ Niño in recent decades (Lee and McPhaden, 2010; Takahashi et al., 2011). In that sense, our study extends the ones by Lagos et al. (2008) and Lavado et al. (2013). Because of the interplay between large-scale and regional oceanic conditions, such relationship is thought to result from the nonlinear interaction between local and remote influences, which a study based on a diversity of indices may help to disentangle. For instance, precipitation events in the Piura region $\left(5^{\circ} \mathrm{S}\right)$ are associated to SST warm episodes along the coast that are not necessary related to EP El Niño events (Woodman, 1985). Simply, former studies have focused on extreme El Niño events that caused large economic losses for Peru, but little has been said on moderate events. In a context of climate change, there is also a clear need to better understand the natural low frequency of the teleconnection pattern. Here, we take advantage of a long-term data record and a revisited interpretation of the ENSO variability over the last five decades, where ENSO is viewed as two distinct and independent regimes, one associated to extreme events, i.e. the case of the 1982/1983 and 1997/1998 strong El Niño events, and the other one associated to moderate warm event and La Niña events (Takahashi et al., 2011).

The paper is organized as follows. The data and methodology used in this study are described in the Data and Methodology sections. We provide the results in the Results section and the conclusions in the Conclusions section.

\section{DATA}

\section{Digital elevation model}

The digital elevation model is obtained from 90-m resolution SRTM data (Shuttle Radar Topography Mission, NASA-NGA, USA) and is available from http://srtm.csi. cgiar.org/SELECTION/inputCoord.asp. It allows delineating the major river watersheds from highlands limits between 
Pacific and Amazon basins to the Pacific coast and also allows checking the location of the meteorological stations.

\section{Precipitation data}

Monthly rainfall data were provided by SENAMHI (National Service of Meteorology and Hydrology of Peru). The longest period available corresponds to 48 years from 1964 to 2011, but some rainfall stations present missing information. Therefore, our database includes 52 meteorological stations with a maximum of missing information around 5\% covering the whole Peruvian coast from northern to centre.

The stations are located along all the Pacific coast and their elevations vary from 1 (e.g. Puerto Pizarro station) to $4406 \mathrm{~m}$ asl (e.g. Choclococha station). Because of this latitudinal and altitudinal dispersion (Figure 1), we propose a standard process for data quality assessment, data completion and regionalization processes.

We defined regions for grouping stations into climatological homogeneous zones, on the basis of the regional

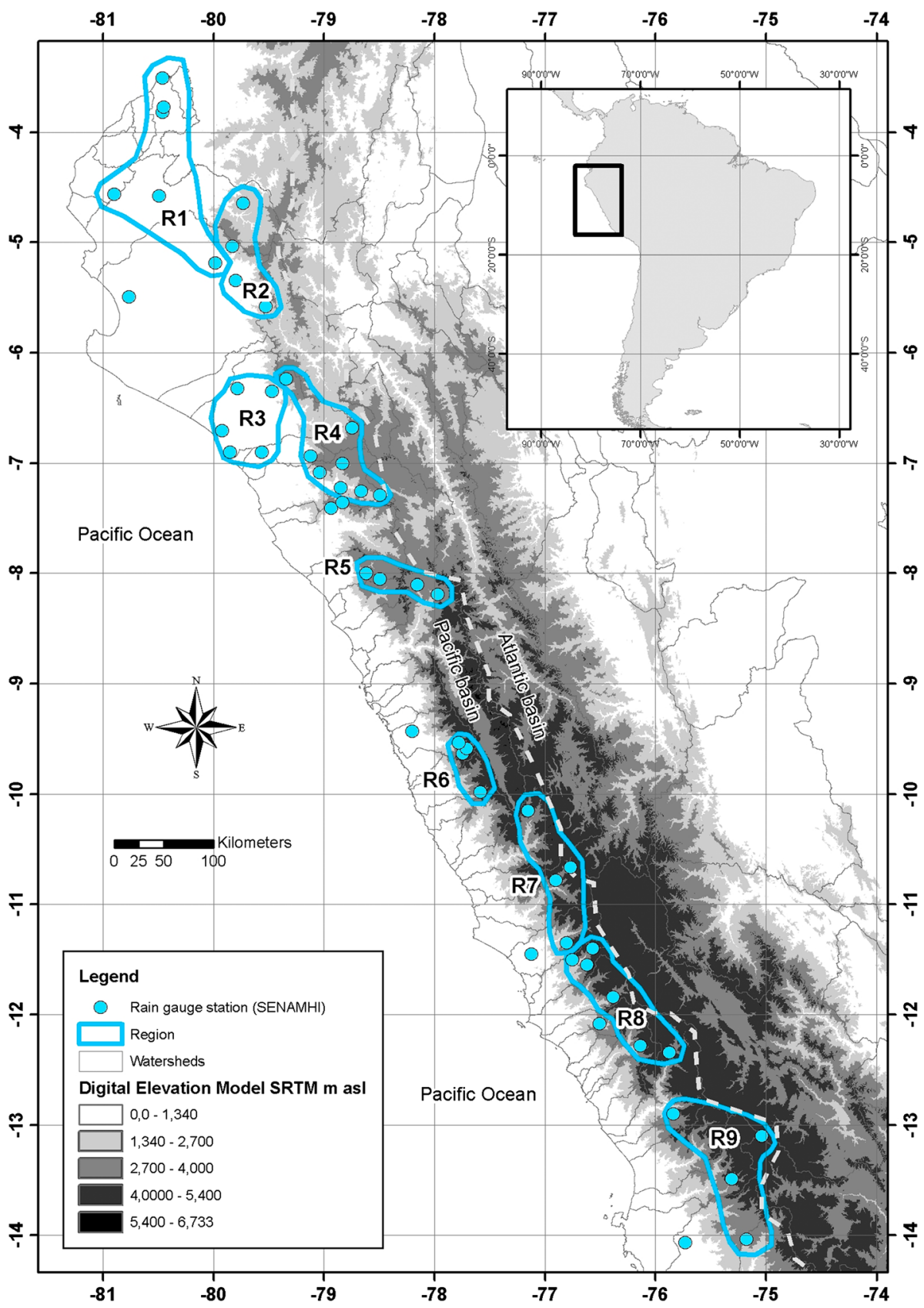

Figure 1. Altitude and location map of the meteorological stations (in situ data, SENAMHI). Location of the nine regions (cyan contours). The heights come from the digital elevation model SRTM with $90 \mathrm{~m}$ of resolution 
vector methodology (Brunet-Moret, 1979), which consists in assuming that for the same climatic zone under the same rainfall regime, the total annual rainfall is pseudo proportional, with a little random variation due to rain distribution in the zone. Then, we complete our series and obtain for each region a representative time series. The algorithm is briefly described as follows:

1. Identification of regional vectors by considering the statistical and hydrographic criteria (elevation, watershed boundaries and latitude). Here, we use a linear correlation between the regional vector obtained and the series of months to complete.

2. If a significant correlation is not reached, we conducted an analysis of linear correlation between the stations of a region for a given month.

3. If a significant correlation is not reached at level 2, we compared monthly hyetographs between neighbouring stations of a region and complete the missing monthly data.

4. Finally, in the case of a normal event (i.e. not El Niño event), we reconstructed the series replacing each monthly precipitation value by the corresponding interannual mean monthly value calculated for all the periods (including an arbitrary small noise on the mean and standard deviation of the value).

5. Otherwise, it is not recommended to complete the missing months.

Once the data completion process is validated, we estimated the average monthly precipitation for each region for the entire period of 48 years, using classical interpolation methods such as Thiessen, inverse distance and Kriging. To present our results, we used the Kriging technique, which leads to the most accurate estimates (von Storch and Zwiers, 2003).

For all our study, we used the yearly averaged precipitation data, which correspond to the annual hydrological cycle spanning from September to August.

\section{ENSO indices}

We use classical monthly ENSO indices (Kiem and Franks, 2001) derived from databases of the NOAA (Climate Prediction Center): SST $1+2$ (NINO 1 + 2), SST 3 (NINO 3), SST 4 (NINO 4), SST 3.4 (NINO 3.4) and Southern Oscillation Index (SOI ). We used non-standardized monthly anomalies.

The preliminary stage is to identify periods of extreme ENSO events (El Niño and La Niña), using the distribution of positive or negative values of each of conventional indices used to characterize ENSO (SOI and SST); in the same way, we also identified these periods from excesses and deficits of precipitation on each region.
Former studies show that there is a close relationship between the development of El Niño and a SOI fall (negative values) and an increase (positive values) of SST indices (Lagos and Buizer, 1992; Lagos et al., 2008; Lavado et al., 2013). Kiem and Franks (2001) mention two methods for identifying ENSO events. The first method consists in identifying the years when the SOI is above or below its average value for a minimum period of 5 months consecutive. The second method is the same as the first method but using indices based on SST anomalies instead of the SOI index.

Whereas these indices are commonly used for ENSO impact studies, they are not completely appropriate for characterizing the different types of El Niño that have been documented in recent years (Ashok et al., 2007; Kug et al., 2009). In our study, in the aim to select the ENSO indices that best explain the precipitation, we performed the principal component analysis (PCA) method (see more details on the PCA method in the Principal Component Analysis section). It is illustrated in Figure 2 that most indices have a large projection on SST3 (i.e. the angle between the indices and SST3 is less than $45^{\circ}$ ), which indicates that they are all highly correlated. Only the SST1 +2 index that accounts for extreme and/or coastal El Niño has a weak projection on the SST4 index (i.e. the two indices are almost orthogonal).

In a recent study (Takahashi et al., 2011), two new indices were proposed, the so-called $\mathrm{E}$ and $\mathrm{C}$ indices that can describe two regimes of variability accounting for extreme warm events (or EP El Niño) and moderate events (La Niña and CP El Niño), respectively. These

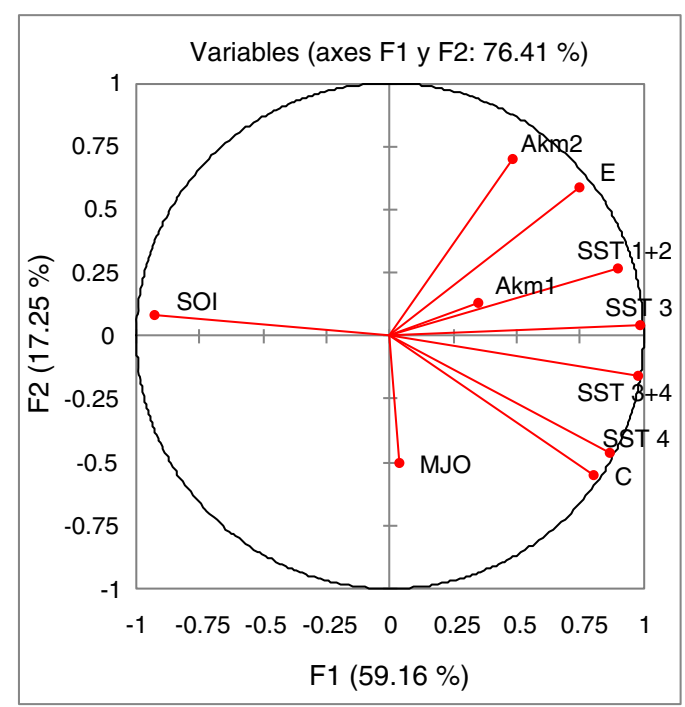

Figure 2. Projection of El Niño Southern Oscillation indices into a principal component analysis (PCA). Note that the E and $\mathrm{C}$ indices are by construction orthogonal on the basis of the monthly averaged data. For the PCA, averaged data from September to February were used 
indices are by construction independent (orthogonal). They are comparable with the SST1 +2 and SST4 indices respectively (Figure 2). The E index accounts for the SST variability in the far eastern Pacific and captures very clearly the two strong El Niño over the data record used in this study, namely, the 1982/1983 and 1997/98 El Niño. Therefore, correlation analysis using this index will emphasize the relationship for extreme events. By construction, the $\mathrm{C}$ index is orthogonal to the $\mathrm{E}$ index, the correlation analysis using this index will emphasize the relationship between precipitation variability and moderate El Niño and La Niña events. Note that the $\mathrm{E}$ and $\mathrm{C}$ indices were calculated from monthly mean values and we considered the mean over SONDJF for the PCA (Figure 2), so that they do not appear strictly orthogonal.

\section{MJO and equatorial ocean Kelvin wave activity indices}

The motivation for using such indices lies in part to the possibility that different regimes of atmospheric circulation may take place over the different regions because of their distinct elevation. In particular, the western coast of Peru is embedded in the large-scale subsidence zone corresponding to the descending branch of the Walker circulation, leading a shallow marine boundary layer propitious to the development of low-level clouds. Thus, conversely to the region over the Andes where deep convection and advection of humidity from the Amazon basin can take place, the coastal region is characterized by a relatively stable air column, implying dry mean conditions. Still, at $2000 \mathrm{~m}$ asl, deep convection associated to largescale disturbances (e.g. MJO) or/and orographic-induced circulation can take place, which is associated to precipitation. On the other hand, where SST near the coast reaches a threshold from which deep convection can occur, local precipitation events can be generated. Such events may be thus triggered by SST anomalies induced by the crossing of equatorial Kelvin waves.

MJO activity index. Atmospheric circulation in the region of Peru is also influenced by atmospheric conditions not necessarily directly related to ENSO but to local ocean conditions in the central-western Pacific. The MJO (Madden and Julian, 1972) is a tropical global scale atmospheric disturbance and the dominant tropical intraseasonal mode. It is a key source of untapped predictability in both the tropics and extratropics (Wheeler and Kiladis, 1999; Wheeler and Weickmann, 2001; Waliser et al., 2003; Waliser, 2005; Gottschalck and Higgins, 2008). The MJO can propagate from the western Pacific to the South American continent, which can alter the tropospheric circulation all over the tropical band, with a potential impact on precipitation over the South American continent. Because MJO is a circumnavigating wave, it can modify the regional atmospheric circulation in northern Peru by altering the well-stratified air above a shallow inversion zone in this region due to the coastal upwelling. In particular, the inversion zone near the coast lies around the $900 \mathrm{hPa}$ isobar below which low clouds (stratocumulus) generally develop. MJO-related variability is also found in the midlatitudes of the Southern Hemisphere and modulates the South-Pacific anticyclone, which variability is influential on the atmospheric circulation off central Peru (Dewitte et al., 2011a, b). At last, MJO is tightly linked to ENSO (Roundy and Kiladis, 2006), and its activity may also reflect ENSO property changes (Gushchina and Dewitte, 2012).

In this study, we use an MJO activity index following the method by Wheeler and Kiladis (1999), which consists in extracting the energy bivariate space-time spectral analysis (Hayashi, 1982) of outgoing longwave radiation in the frequency-space domain of the MJO over the tropical belt. The MJO-filtered time series is then used to define an MJO activity index by taking the variance over a 3-month running window and averaging over the region where its variability peaks. Typically, an MJO activity index is defined by averaging over the western central Pacific along the equator $\left(5^{\circ} \mathrm{S}-5^{\circ} \mathrm{N} ; 120^{\circ}-180^{\circ} \mathrm{E}\right)$ (McPhaden et al., 2006; Gushchina and Dewitte, 2012). We choose here to remove the annual cycle by a wavelet multiresolution filtering (Labat et al., 2000). Summarizing the MJO activity index used in the paper accounts for the periods when there is an enhanced or reduced variability of the MJO. When this index is larger than usual (positive anomaly), this means that more highfrequency fluctuations of tropical Pacific origin may reach the Peru coast and lead to precipitation anomalies on average along the coast.

Oceanic regional indices. The MJO is also associated to the formation of Westerly Wind Burst (Vecchi and Harrison, 2000) in the equatorial western central Pacific that can trigger planetary oceanic waves, called equatorial Kelvin wave. The energy of these planetary oceanic waves is within the intraseasonal frequency band, i.e. [2-120] days ${ }^{-1}$ (Dewitte et al., 2008). We will refer to these intraseasonal Kelvin waves as intraEKW hereafter. They should not be confused with the interannual Kelvin waves that are forced when El Niño develops, i.e. when the atmospheric circulation in the tropics interacts with the warm SST anomalies, leading to energetic westerlies at interannual timescales. The interannual Kelvin waves, named interEKW hereafter, are tightly linked to ENSO in the tropical Pacific and therefore do not convey more information than say the $\mathrm{E}$ and $\mathrm{C}$ indices. The intraEKW is active also during ENSO but presents a seasonal modulation depending on the nature of ENSO (Gushchina and Dewitte, 2012). It propagates from the central Pacific to the coast of Ecuador and locally can modify the 
oceanographic conditions along the coast of Peru (Dewitte et al., 2012). For instance, a downwelling intraEKW (i.e. which deepens the thermocline) can produce a warming event along the coast of Peru (see Mosquera et al. (2013) for the $2002 \mathrm{El} \mathrm{Niño),} \mathrm{which} \mathrm{in} \mathrm{turn} \mathrm{may} \mathrm{favour} \mathrm{local}$ convection leading to intense rainfall events (Woodman, 1985). Therefore, change in intraEKW activity can be reflected in the precipitation fluctuations at interannual timescales through its impacts on coastal SST. The intraEKW may be associated to episodic warm/cold events along the coast that are not related in a straight-forward manner to ENSO. In this study, we define an intraEKW cumulative index that is aimed at quantifying the integrated effect of an intraEKW along the coast. The concept is similar to cumulative upwelling index defined by Bograd et al. (2009) but for the oceanic Kelvin wave is based on the idea that, whereas a downwelling intraEKW will favour a warming along the coast, the opposite phase (upwelling) will induce cooler conditions along the coast, not favourable for precipitation. Over a year, the cumulative effect of the intraEKW can be estimated by considering the integration of the skewness of the intraEKW over the period that encompasses the Austral summer season (i.e. when intraEKW activity usually peaks, cf. Dewitte $e t$ al. $(2011 a, b))$. This index is therefore defined as

$$
C_{E K W}^{n}(y)=\int_{D-6}^{D+6}\left(\operatorname{IntraEK} W^{n}\left(x=90^{\circ} W, t\right)\right)^{3} \cdot d t
$$

where $D$ is the month of December of the year $y, t$ is in days and $n$ refers to the type of the waves. Two types of waves will be considered here that differ from their vertical structure and phase speeds along the equator. These waves, which are the most energetic in the equatorial Pacific, will be referred to as $n=1$ or $n=2$ waves (i.e. EKW1 and EKW2). Note that the $C_{E K W}^{1}$ (hereafter Akm1) and $C_{E K W}^{2}$ (hereafter Akm2) indices also reflect the ENSO amplitude and evolution at basin scale because intraEKW is linked to ENSO (Hendon et al., 2007; Gushchina and Dewitte, 2012).

The intraEKWs are derived from an oceanic reanalysis (SODA) over the period 1958-2008. The method consists in projecting the zonal current and pressure anomaly field on the theoretical wave structures as estimated from the mean stratification of the oceanic reanalysis. Details on the method can be found in Dewitte et al. (2008).

We worked with the ten indices described earlier (see Table I for a summary). However, considering the interrelationship between indices, we will focus on five indices that exhibit significant correlation with precipitation fluctuations. Please note that all the results presented in this paper correspond to the yearly averaged data, from September to February for the ENSO indices.

\section{METHODOLOGY}

\section{Principal component analysis}

The selection of ENSO indices that best explain rainfall indices was performed using the PCA, a factorial method of data analysis, which explores the connections between variables to be studied as a whole, to highlight possible correlations (Lagarde, 1983; von Storch and Zwiers, 2003).

\section{The wavelets and coherence analysis}

To study the periodicity of the series (ENSO indices and precipitation), we used wavelet analysis. For a more extensive review of wavelet theory and applications, the reader is referred to Labat et al. (2000) or Labat (2005).

Table I. List of indices used in the paper

\begin{tabular}{|c|c|c|c|c|}
\hline Name & Methods & Aims & Data sources & References \\
\hline $\begin{array}{l}\text { SST1 + } 2 \text { SST3 } \\
\text { SST3.4 SST4 }\end{array}$ & $\begin{array}{l}\text { Averaged SST over tropical } \\
\text { Pacific sectors }\end{array}$ & $\begin{array}{l}\text { Characterizing the El Niño } \\
\text { with classical indices }\end{array}$ & ERSST.V3B & Kiem A. and Franks S (2001) \\
\hline SOI & $\begin{array}{l}\text { Based on pressure level } \\
\text { differences between Tahiti } \\
\text { and Darwin locations in the } \\
\text { tropical Pacific. }\end{array}$ & $\begin{array}{l}\text { Characterizing the El Niño } \\
\text { canonical }\end{array}$ & NOAA & $\begin{array}{l}\text { Rasmusson and Carpenter } \\
\text { (1982) }\end{array}$ \\
\hline $\mathrm{E} / \mathrm{C}$ & $\begin{array}{l}\text { Based on the first two EOF } \\
\text { modes of SST in the tropical } \\
\text { Pacific }\end{array}$ & $\begin{array}{l}\text { Characterizing the two types } \\
\text { of El Niño }\end{array}$ & HadiSST & Takahashi et al. (2011) \\
\hline MJO & $\begin{array}{l}\text { Wavelength-frequency (w-k) } \\
\text { decomposition and } \\
\text { recomposition in the MJO } \\
\text { w-k domain }\end{array}$ & $\begin{array}{l}\text { Characterizing regional } \\
\text { atmospheric circulations } \\
\text { related to MJO }\end{array}$ & $\begin{array}{l}\text { NCEP/NCAR } \\
\text { reanalysis }\end{array}$ & Wheeler and Kiladis (1999) \\
\hline Akm1/Akm2 & $\begin{array}{l}\text { Two baroclinic modes, Akm } 1 \\
\text { and Akm } 2 \text { are considered as } \\
\text { the most energetic Kelvin } \\
\text { waves }\end{array}$ & $\begin{array}{l}\text { Characterizing oceanographic } \\
\text { conditions related to El Niño } \\
\text { and coastal SST anomalous } \\
\text { conditions }\end{array}$ & $\begin{array}{l}\text { Simple Ocean } \\
\text { Data Assimilation } \\
\text { (SODA) reanalysis }\end{array}$ & Dewitte et al. (2008) \\
\hline
\end{tabular}


The basic aim of wavelet analyses is both to determine the frequency (or scale) content of a signal and to assess and determine the temporal variation of this frequency content (Heil and Walnut, 1989). Therefore, the wavelet transform is the tool of choice when signals are characterized by localized high-frequency events or when signals are characterized by a large number of scalevariable processes. Because of its localization properties in both time and scale, the wavelet transform allows for tracking the time evolution of processes at different scales in the signal. This time-scale wavelet transformation $C_{\psi}^{x}(a, \tau)$ is defined in the case of a continuous time signal as

$$
C_{\psi}^{x}(a, \tau)=\frac{1}{\sqrt{a}} \int_{-\infty}^{+\infty} x(t) \cdot \psi^{*}\left(\frac{t-\tau}{a}\right) d t
$$

where $*$ corresponds to the complex conjugate. The function $\psi(t)$, which can be real or complex, plays the role of a convolution kernel and is called a wavelet.

The parameters $a$ and $\tau$ are used to adjust the shape and location of the wavelets respectively in scale and time domains. Changing $t$, e.g. allows for moving the centre of the wavelet. Then, the wavelet transform is a sort of microscope with magnification 1/a and location given by the parameter $\tau$.

Then, another concept is also used: the wavelet coherence. Classically, the notion of coherence in signal processing consists of a measure of the correlation between two signals or between two representations of these signals.

Here, we will use the wavelet coherence of two signals defined by Torrence and Webster (1999). They propose to determine wavelet coherence between two signals $X(t)$ and $Y(t)$ using a smooth estimate of the wavelet spectrum and to define a smooth wavelet spectrum and cross spectrum, respectively noted $S W_{X X}(a, \tau)$ and $S W_{X Y}(a, \tau)$

$$
\begin{aligned}
& S W_{X X}(a, \tau)=\int_{t-\delta / 2}^{t+\delta / 2} W_{X X}^{*}(a, \tau) W_{X X}(a, \tau) d a d \tau \\
& S W_{X Y}(a, \tau)=\int_{t-\delta / 2}^{t+\delta / 2} W_{X X}^{*}(a, \tau) W_{Y Y}(a, \tau) d a d \tau
\end{aligned}
$$

The scalar $\delta$ represents the size of the two-dimensional filter, used for time and scale averaging as a necessary step for coherence calculation. The wavelet coherence $W C$ can then be defined by analogy with Fourier coherence as

$$
W C(a, \tau)=\frac{\left|S W_{X Y}(a, \tau)\right|}{\sqrt{\left[\left|S W_{X X}(a, \tau)\right| \cdot\left|S W_{Y Y}(a, \tau)\right|\right]}}
$$

A temporal mean of the wavelet coherence can also be relevant in order help to identify ENSO indices that have a major influence on precipitation variability from a global point of view.

\section{Correlation analysis}

The correlation analysis is used to estimate the ENSOprecipitation relationship. The significance of the correlation coefficients was estimated using a $t$-test.

Correlation analysis was first performed for the monthly averaged anomalies relative to the mean seasonal cycle over the whole record. Because the rainy season for the coastal regions is concomitant with the periods when precipitation anomalies are the strongest, the results are similar if the correlation analysis is performed for the yearly averaged data, which corresponds to the annual hydrological cycle spanning from September to August. ENSO indices where averaged over September to February, which corresponds to the ENSO extended peak phase. The results of the correlation analysis presented in this paper correspond to the yearly averaged data, respectively from September to August for precipitation and from September to February for the ENSO indices.

\section{RESULTS}

\section{Regionalization of precipitations}

The basin's mean altitude levels vary from the sea level up to more than $4000 \mathrm{~m}$ (Andes). In some cases, there are glaciers and peaks above $6000 \mathrm{~m}$. Hydrological year covers the period from September to August for all the watersheds and does not change with latitude.

Using the regional vector methodology, nine climatically homogeneous regions (R1 to R9) are identified. We can note that there are five rainfall gauge stations along the coast (northern to centre) that do not belong to any of nine regions identified with the regional vector because they present a strong intermittent regime. Anyway, we have taken into account these five stations in Figure $3 \mathrm{~b}$ to complete our downstream dataset along the coast. In the rest of the study, these five isolated rainfall gauges are not considered. We only work with the nine identified regions.

According to Figure 1 and Table II, each region is characterized by an uninterrupted series of mean monthly precipitation considering the full set including the years of strong El Niño events, namely, 1982/1983 and 1997/ 1998. Table II shows two series (including and excluding the strong ENSO episodes) of the yearly averaged data over 1964-2011 period, and we show on Figure 3a the mean monthly rainfall distribution for the nine regions not considering ENSO events.

In Figure $3 \mathrm{~b}$, we can see that the nine regions are distributed in two groups of regions corresponding to downstream regions (R1 and R3 and remaining stations, located along the coast region) and upstream regions (R2, R4 to R9 located in the Andean slopes) from north to south. Downstream (upstream) regions are located below (above) an altitudinal level around $1500 \mathrm{~m}$ asl (Table II) 


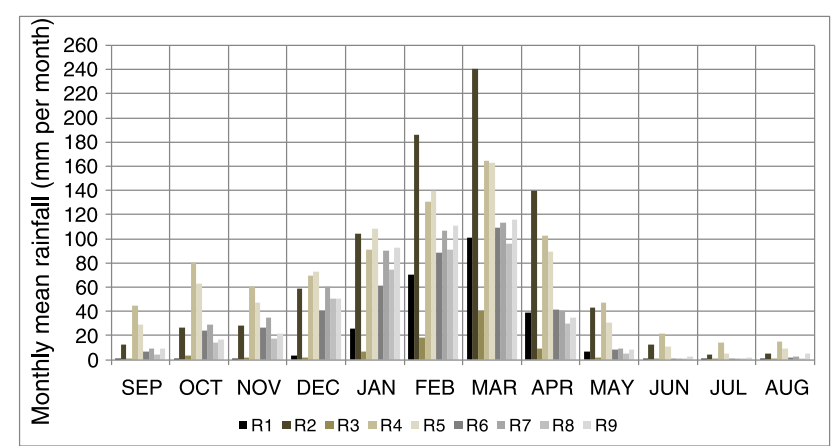

a)

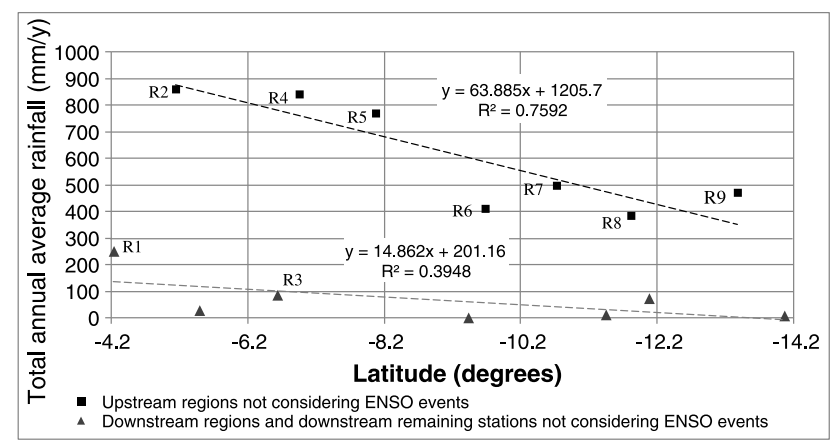

b)

Figure 3. a) Mean monthly rainfall values for the nine regions not considering strong El Niño events (1982/1983 and 1997/1998). b) Total annual rainfall versus latitude (not considering El Niño Southern Oscillation events) showing two groups clearly defined coinciding with upstream and downstream areas

and characterized by a yearly average rainfall below (above) $300 \mathrm{~mm} /$ year (Figure 3b).

Figure $3 \mathrm{~b}$ illustrates too that the annual precipitation increases with the altitude (Table II) and decreases with latitude (from north to centre).

\section{Coherence between ENSO indices and precipitation series}

Wavelet analysis for precipitation series (from R1 to R5) through the scale band between 2 and 16 years has allowed identifying clearly the strong events over the period 1964-2011, which are the 1982/1983 and 1997/ 1998 El Niño events (see Figure 4a for R1). Without considering these strong events, we can identify events of lower intensity and higher frequency (see Figure $4 \mathrm{~b}$ for $\mathrm{R} 1)$. We also note that the influence of these strong events is not clear from R6 to R9 (see Figure 4c for R6). For all nine regions, the major peaks are located in the period bands of 2-4, 4-8 and 8-16 years. We implement the classical statistical significance estimation based on comparison with red noise (Torrence and Webster, 1999). We choose here an $80 \%$ statistical significance based on the relative shortness of the data. For example, similar statistical significances were used by Labat (2006). The $80 \%$ threshold was chosen here in order to get statistical significance on all the three peaks mentioned (2-4, 4-8 and 8-1 years).

In the same way, the ten ENSO indices for the period 1964-2011 show that ENSO events are also associated to periods in the range of $2-4,4-8$ and $8-16$ years. These results are consistent with those of other authors (Diaz and Markgraf, 2000), which showed that the ENSO periodicity has three dominant modes of frequency variation: quasi-biennial, quasi-quadrennial and quasidecadal (see Figure 4d for E index). That also confirms that the quasi-biennial and quasi-quadrennial modes are dominant in the Intertropical Convergence Zone (Lagos and Buizer, 1992).

The wavelet analyses suffer here from the classical 'cone influence issue', i.e. the region of the wavelet spectrum in which edge effects become important and make questionable the possible interpretation of the wavelet analysis. Then, the wavelet analysis gives only unquestionable results on the 1977-2000 interval for scales larger than 16 years. Therefore, even though if the validity of the presence of the 16-year oscillation may be questionable, the absence of discontinuity in the 16-year spectral band on the time intervals corresponding to the cone of influence suggests that this oscillation is present over all the 1964-2011 time interval.

Table II. Description of the nine climatically homogeneous regions

\begin{tabular}{lccclcr}
\hline Region & $\begin{array}{c}\text { Mean } \\
\text { latitude } \\
\text { (south) }\end{array}$ & $\begin{array}{c}\text { Minimal } \\
\text { elevation } \\
\text { (m asl) }\end{array}$ & $\begin{array}{c}\text { Maximal } \\
\text { elevation } \\
\text { (m asl) }\end{array}$ & \multicolumn{1}{c}{$\begin{array}{c}\text { River } \\
\text { watershed }\end{array}$} & $\begin{array}{c}\text { Total annual rainfall } \\
\text { including El Niño } \\
\text { years (mm) }\end{array}$ & $\begin{array}{c}\text { Total annual rainfall } \\
\text { excluding El Niño } \\
\text { years (mm) }\end{array}$ \\
\hline R1 & $4.23^{\circ}$ & 1 & 440 & Tumbes-Piura & 386.8 & 250.5 \\
R2 & $5.15^{\circ}$ & 480 & 2740 & Chira-Piura upstream & 924.6 & 862.0 \\
R3 & $6.63^{\circ}$ & 18 & 500 & Chancay & 130.4 & 86.7 \\
R4 & $6.96^{\circ}$ & 850 & 3030 & Motupe-Jequetepeque & 77.7 & 769.1 \\
R5 & 8.08 & 2580 & 3460 & Moche-Nord Santa & 420.4 & 409.2 \\
R6 & 9.68 & 2285 & 3570 & Casma-Huarmey & 498.7 & 398.5 \\
R7 & $10.74^{\circ}$ & 2333 & 3950 & Pativilca-Huaral & 384.1 & 384.5 \\
R8 & $11.82^{\circ}$ & 2479 & 3875 & Chillon-Cañete upstream & 467.6 & 470.7 \\
R9 & $13.38^{\circ}$ & 2533 & 4406 & Cañete-Ica & & \\
\hline
\end{tabular}



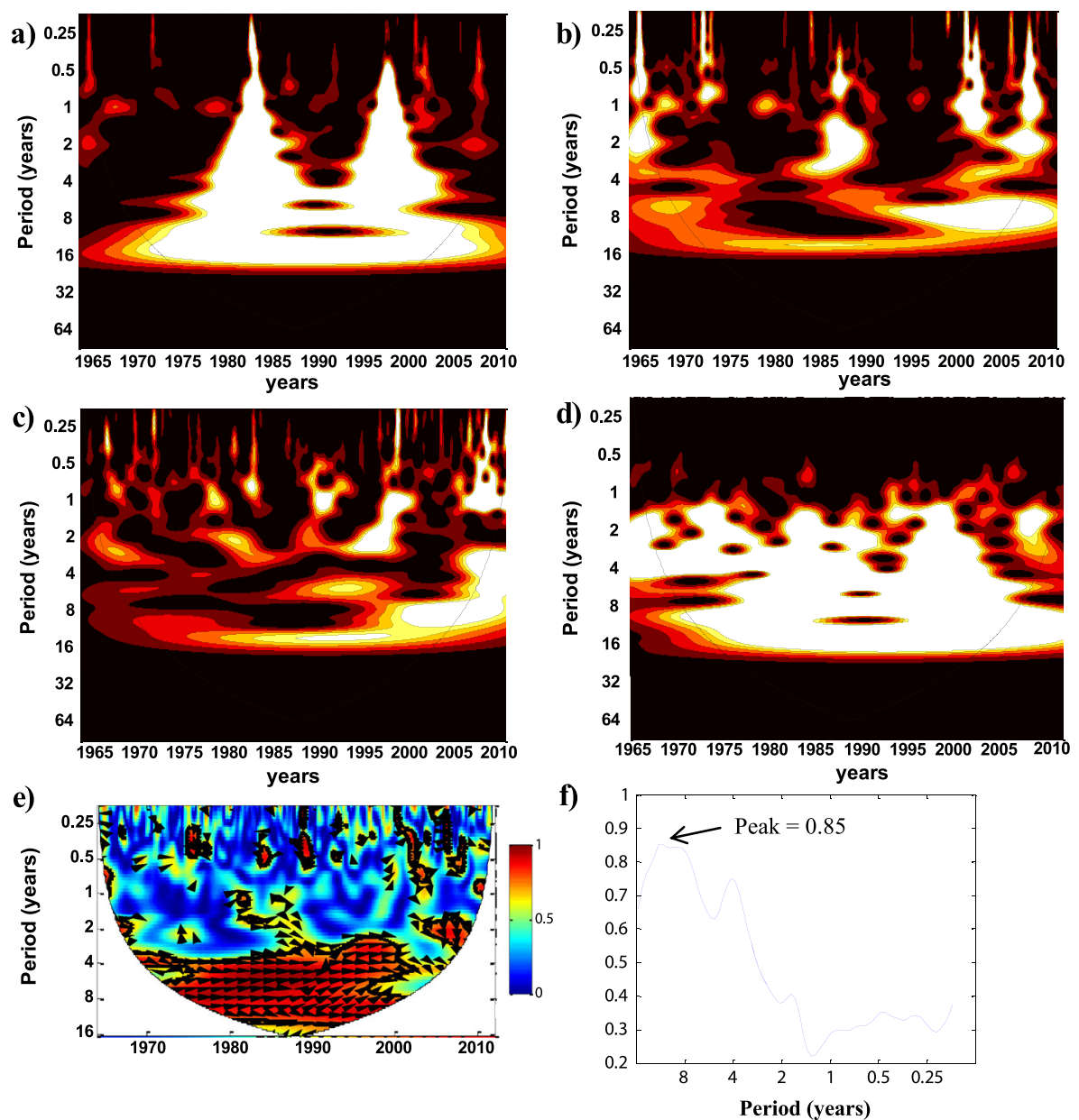

Figure 4. a) Wavelet of R1 precipitation, b) wavelet of R1 precipitation not considering strong El Niño events, c) wavelet of R6 precipitation, d) wavelet of $\mathrm{E}$ index, e) wavelet coherence between $\mathrm{E}$ index and R1 precipitation and f) mean coherence peaks for wavelet coherence between $\mathrm{E}$ index and R1

The wavelet coherence analysis between ENSO indices and precipitation series allowed us to quantify the relation between an ENSO index and precipitation over a region. The vectors in black on Figure $4 \mathrm{e}$ indicate the values of the phase shift between two time series. Thus, a vector pointing to the right shows a direct relation, whereas a vector pointing left indicates an inverse relation (negative correlation). Figure $4 \mathrm{e}$ displays the wavelet coherence of $\mathrm{R} 1$ precipitation and $\mathrm{E}$ index, which shows a strong coherence (red coloration); the average maximum coherences are above 0.8 for periods of 4-16 years (Figure 4f), for quasi-decadal and quasi-quadrennial periods with a change of phase (change of direction of the arrows) in periods of $8-16$ years.

Table III provided the values of maximal coherence for all regions. Interestingly, all maximal coherences are found at the decadal frequency, which indicate that the low-frequency ENSO modulation is the most influential on precipitation along the coast of Peru. This justifies the selection of sub-periods for the correlation analysis (refer to succeeding text). The results also indicate that some indices are more relevant for the northern part of Peru (SST 1+2, SST 3), whereas others are more relevant for regions of central Peru (SST4, SST 3.4). Not surprisingly, the E index exhibits a large coherence from north to centre (R1 to R5) because it accounts for extreme warm events. For MJO, the values of highest coherence are located on the upstream basins (R2, R4, R5 and R6, values between 0.62 and 0.79 ) consistent with the expectation that MJO is influential at relatively high altitudes. For oceanic indices, the Akm1 index is more influential in the north and in the basins downstream of R1 and R3, whereas the Akm2 index has the largest coherence with R1 and R2. Coherence values for the region R9 are not significant for any index: they are lower than 0.50, and the highest is that of the MJO (0.49).

\section{Low-frequency modulation of ENSO and precipitation regime}

The two main climate shifts in the tropical Pacific over the last five decades include the 1976/1977 climate shift (Miller et al., 1994; others) and, more recently documented, 
Table III. Summary of maximal coherences for each region (in all cases, coherences correspond to quasi-decadal frequency)

\begin{tabular}{|c|c|c|}
\hline Latitude ${ }^{\circ}$ sur & Region & Wavelet coherence ENSO indices with maximal coherences (c) \\
\hline $4.23^{\circ}$ & $\mathrm{R} 1$ & $\begin{array}{l}\text { SST } 1+2(c=0.84), \text { SST } 3(c=0.69), \text { SST } 4(c=0.61), \text { SST } 3.4(c=0.65), \\
\text { MJO }(c=0.55), \text { SOI }(c=0.58), E(c=0.85), C(c=0.73), \text { Akm } 1(c=0.68), \text { Akm2 }(c=0.70)\end{array}$ \\
\hline $5.15^{\circ}$ & $\mathrm{R} 2$ & SST $1+2(c=0.62)$, SST $4(c=0.58)$, MJO $(c=0.72), E(c=0.83), C(c=0.68), \operatorname{Akm} 2(c=0.54)$ \\
\hline $6.63^{\circ}$ & R3 & SST $1+2(c=0.54)$, SST $4(c=0.53)$, MJO $(c=0.66), E(c=0.79), C(c=0.65)$, Akm1 $(c=0.60)$ \\
\hline $6.96^{\circ}$ & R4 & SST $4(c=0.55)$, SST3.4 $(c=0.50)$, MJO $(c=0.69), E(c=0.59), C(c=0.50)$ \\
\hline 8.08 & R5 & $\mathrm{MJO}(\mathrm{c}=0.62), \mathrm{E}(\mathrm{c}=0.66)$ \\
\hline 9.68 & R6 & MJO $(c=0.79), E(c=0.48)$ \\
\hline $10.74^{\circ}$ & $\mathrm{R} 7$ & SST $4(c=0.58)$, SST3.4 $(c=0.55), C(0.51)$ \\
\hline $11.82^{\circ}$ & $\mathrm{R} 8$ & SST $4(c=0.50), E(c=0.71), C(c=0.52)$ \\
\hline $13.38^{\circ}$ & R9 & SST $1+2(c=0.40)$, SST $4(c=0.40)$, MJO $(c=0.49)$ \\
\hline
\end{tabular}

the 2000 shift when the mean state became cooler (Tsonis et al., 2007; Luo et al., 2012; McPhaden, 2012; Xiang et al., 2012, Hong et al., 2013). Change in mean SST is influential on the teleconnection pattern and may impact precipitation at the regional scale. Here, as a first step, we consider three periods corresponding to these two transitions: P1 (1964-1976), P2 (1978-1999) and P3 (2000-2011). Instantaneous correlation analyses are carried out between the five indices (Table $\mathrm{I}$ ) and the nine regions ( $\mathrm{Ri} ; \mathrm{i}=1,2, \ldots 9)$. We retain results for the $\mathrm{E}, \mathrm{C}, \mathrm{Akm} 1, \mathrm{Akm} 2$ and $\mathrm{MJO}$ indices considering that the $\mathrm{E}$ and $\mathrm{C}$ indices grasp the behaviour of other indices based on SST through linear combination (Takahashi et al., 2011) and that the other ones account for specific oceanographic and atmospheric processes (see section on Data). Figure 5 displays the results. For the P2 period, we provide statistics with and without extreme events, which indicates that the known relationship between precipitation and ENSO over northern Peru (Lagos et al., 2008 ) is mostly the result of the influence of the two El Niño events of 1982/1983 and 1997/1998. For instance, the correlation over the regions $\mathrm{R} 1$ to $\mathrm{R} 3$ is above 0.7 for the $\mathrm{E}$ index and the Akm2 index when these events are considered (Figure 5a). These correlations remain hardly significant when the events are not considered (Figure $5 \mathrm{~b}$ - middle). Interestingly, the MJO index is almost insensitive to the consideration of extreme events with correlation value above the significance level for all Ri except R1, whereas the $\mathrm{C}$ index exhibits a relatively large correlation (significant) in some regions when the influence of extreme events is removed.

Another interesting feature arising from the results of Figure 5 is the significant change in correlation according to the period under consideration for some indices. In particular, the $\mathrm{C}$ index and $\mathrm{Akm} 1$ index become more influential on precipitation during $\mathrm{P} 3$ on average over the regions. The $\mathrm{C}$ index exhibits a large correlation with precipitation over the regions R6 to R9 during P3. On the other hand, the MJO index exhibits a reduced correlation with precipitation over P3 compared with P2. Besides the low-frequency modulation of the correlation, a large latitudinal variability is also observed, which is difficult to interpret.
Regarding the oceanic Kelvin waves, first of all, from Figure 2, Akm1 and Akm2 indices have a comparable behaviour than the SST $1+2$ and $\mathrm{E}$ indices, verifying their influence on coastal conditions changes. In particular, when we consider the strong El Niño events of 1982/1983 and 1997/1998 (Figure 5a), the Akm2 index has a comparable relationship with precipitation than the $E$ index, i.e. large correlation in the northern part of Peru that decreases southward. The Akm2 index captures well the peak of strong El Niño (Dewitte et al., 2012) where the Akm1 index is more relevant for intraseasonal Kelvin activity prior to the development of strong El Niño (Gushchina and Dewitte, 2012), which may explain its low correlation with precipitation over the period 1977-1999 dominated by strong El Niño activity. On the other hand, the influence of the first mode Kelvin wave (Akm1) on precipitation increases over the 2001-2011 period (Figure 5b) characterized by both occurrences of central Pacific El Niño and La Niña events. Its influence on precipitation is the largest for the southernmost regions (R6 to R9) and is comparable with the $\mathrm{C}$ index that grasps the central Pacific variability.

Considering the significant decadal variability in the relationship between ENSO and precipitation evidenced earlier, we now investigate if a long-term trend in this relationship can be observed in some regions. We consider here the $\mathrm{E}$ and $\mathrm{C}$ indices. The 11-year running correlation between these two indices and precipitations is presented in Figure $6 \mathrm{a}, \mathrm{b}$ and $\mathrm{c}$ (this leads to a loss of 5 years in the beginning and at the end of the period). Here, again, we will consider the analysis without the 1982/1983 and $1997 / 1998$ extreme events in order to highlight the change in teleconnection pattern associated to moderate warm events. This results in computing the correlation from nine points instead of 11 points over the periods that encompass the 1982/1983 and 1997/1998 El Niño events. Figure 6a indicates that no clear trend can be detected in most regions with a large meridional and temporal variability of the correlation. The E index accounts for SST variability in the far eastern Pacific that can be associated to intraseasonal 


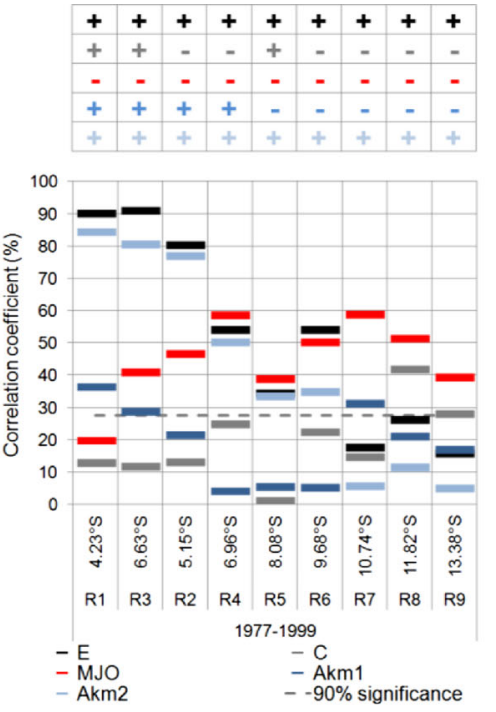

a)
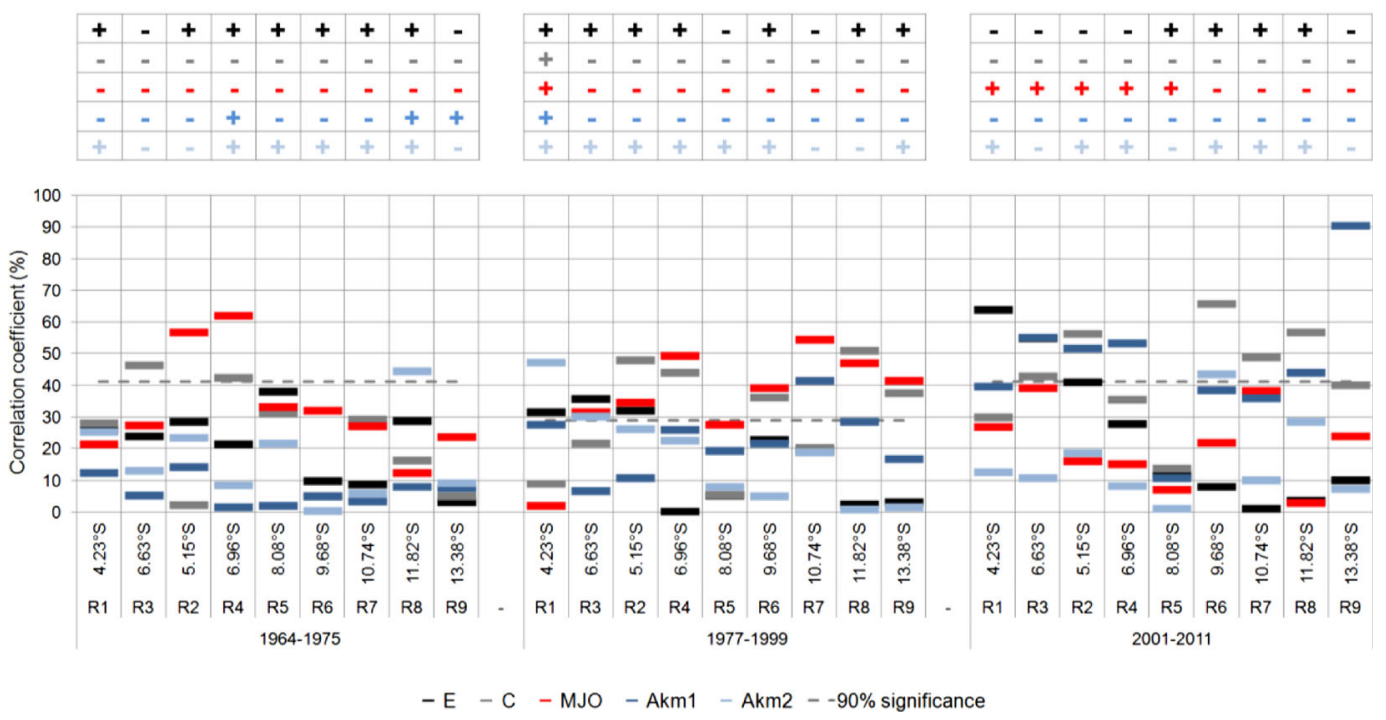

b)

Figure 5. a) Correlation coefficients in absolute value expressed in \% for the 1977-1999 period along latitude and b) idem for 1964-1975, 1977-1999 and 2001-2011 periods, but not considering strong El Niño events (1982/1983 and 1997/1998). The horizontal grey line indicates the significance level at $90 \%$. For Akm1 and Akm2, data only extend until 2008. Absolute values of the correlation are considered to highlight variations as a function of periods. The sign of the correlation is indicated on top of each panel

Kelvin activity and the development of extreme El Niño events such as the 1982/1983 and 1997/1998 El Niño events. Because they are not taken into account in the calculation of Figure 6a, the variable correlation traduces local effects of the either intraseasonal Kelvin waves on SST or local atmospheric perturbations that modify SST along the coast. In order to illustrate the impact of the two extreme El Niño events, a figure similar to Figure $6 \mathrm{a}$ is presented to take them into account (Figure 6b). It clearly shows that statistics are completely changed when these events are considered, with a very high correlation between the $\mathrm{E}$ index and precipitation all over the coast over the period encompassing these events. The central Pacific El Niño, accounted by the $\mathrm{C}$ index, is also characterized by a warming in the eastern Pacific but at a different time in the year (in Austral winter rather than in Austral summer) and with a much less amplitude characterized by a warming in the central Pacific (Dewitte et al., 2011a, b). This warming in the eastern Pacific usually disappears after a few months, and cooling conditions develop (Dewitte et al., 2012). Figure $6 \mathrm{c}$ displays the 11-year mean correlation between the $\mathrm{C}$ index and precipitation. It indicates a more 
a)
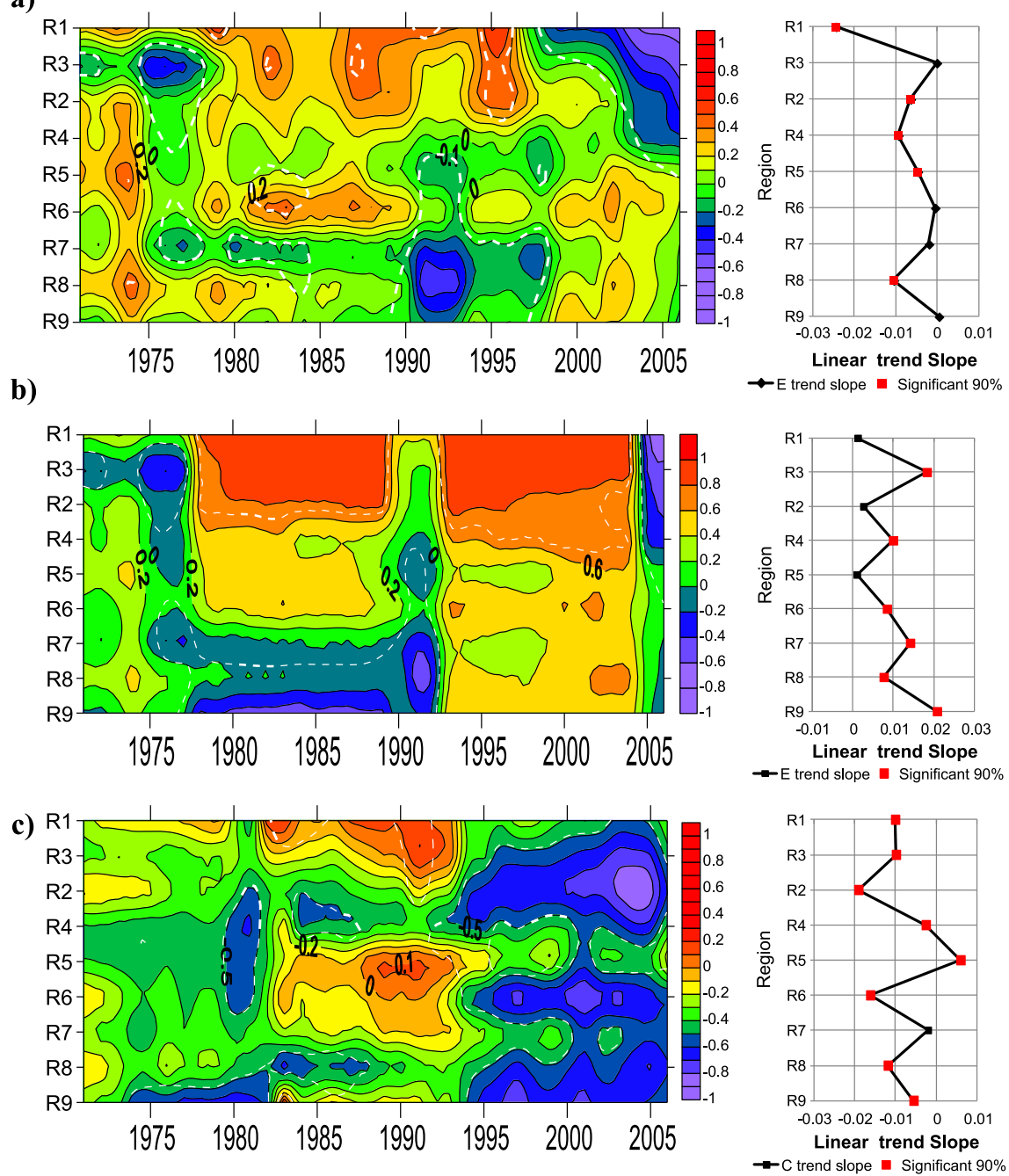

Figure 6. a) Eleven-year running correlation coefficients between the E index and precipitations within each region (R1 to R9) not considering the El Niño Southern Oscillation (ENSO) strong events of 1982/1983 and 1997/1998. The plot on the right hand side displays the slope of the linear trend of the running correlation (red dots indicate that the trend is significant at the $90 \%$ level using a student $t$-test). The white dashed lines indicate the significance level of the correlation at the 75\% level. b) Idem for E index but considering the ENSO strong events of 1982/1983 and 1997/1998 and c) idem for C index not considering the ENSO strong events of 1982/1983 and 1997/1998

contrasted behaviour compared with the E index, with in particular a more clearer decadal modulation of the ENSOprecipitation relationship. In addition, the correlation is mostly negative indicating that central Pacific El Niño activity is associated to drier conditions along the coast of Peru. This situation is emphasized from the 1990s in particular for the regions R2, R6 and R9, with a marked negative trend of the running correlation. The strongest negative correlations and trends are found for the northern region R2 during the 2000s, which corresponds to the period of occurrence of only CP El Niño events.

Our aforementioned interpretation of the low-frequency changes in the relationship between the $\mathrm{E}$ and $\mathrm{C}$ indices and precipitation relies on the assumption that precipitation along the coast of Peru can be influenced by some aspects of the intraseasonal tropical variability both in the ocean and the atmosphere. As a consistency check, we provide comparable analysis than Figure 6 but for the Akm1 and MJO indices (Figure 7). The results indicate that there is also a low-frequency modulation of correlation between the indices and precipitation. The negative trend is obvious for the Akm1 index because of the decrease in correlation from the 1990s in the central and southern regions. This is consistent with the interpretation that intraseasonal downwelling Kelvin wave activity during central Pacific El Niño (Gushchina and Dewitte, 2012) is enhanced, whereas the SST along the coast is reduced from the 1990s. Here, it is not possible to conclude if it is the La-Niña-like mean conditions (leading to cool conditions off Peru) from the 1990s or the coastal cooling associated to central Pacific El Niño that produce the decreased precipitation during 
a)
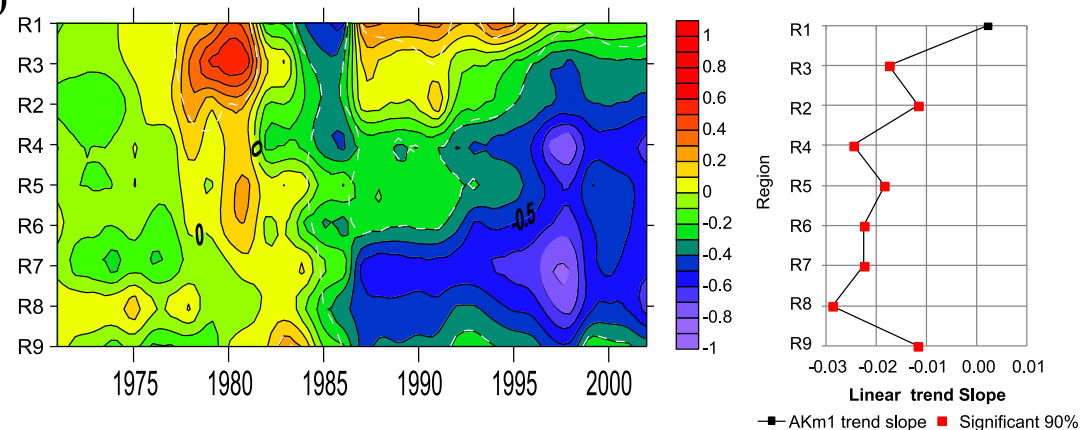

b)
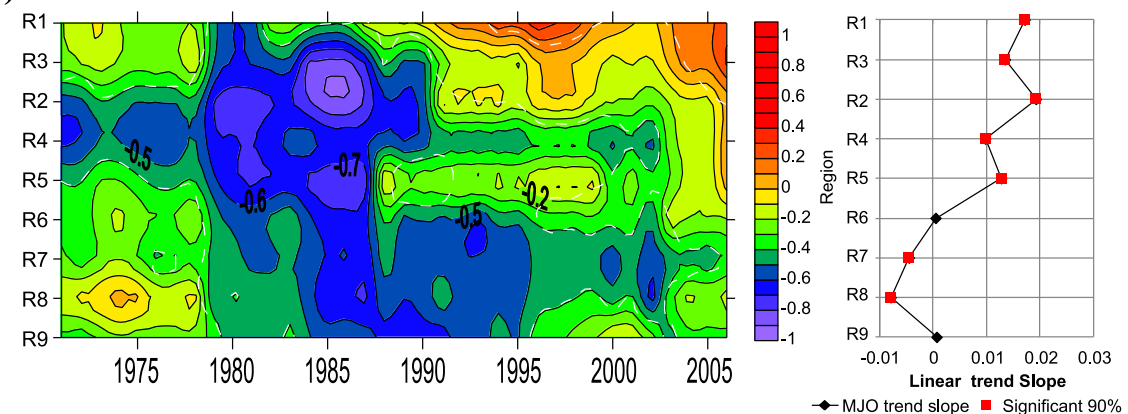

Figure 7. a) Eleven-year running correlation coefficients between the Akm1 index and precipitations within each region (R1 to R9) not considering the El Niño Southern Oscillation strong events of 1982/1983 and 1997/1998. The plot on the right hand side displays the slope of the linear trend of the running correlation (red dots indicate that the trend is significant at the $90 \%$ level using a student $t$-test). The white dashed lines indicate the significance level of the correlation at the $75 \%$ level. b) Idem for Madden and Julian Oscillation index

interannual events. Interestingly, the relationship between precipitation and the MJO index has an opposite trend (i. e. positive), which suggests that the MJO activity leads to increased precipitation in recent years, in particular in the northern regions.

\section{CONCLUSIONS}

In this paper, we used precipitation records from a network of 52 rainfall gauge stations located between $3.5^{\circ} \mathrm{S}$ and $14^{\circ} \mathrm{S}$ and from 0 to $4000 \mathrm{~m}$ from northern to centre of Peruvian Pacific coast over the period 1964-2011. A climate homogenization procedure, based on the regional vector methodology, allows inferring nine regions with monthly precipitation time series, estimated by Kriging interpolation, that exhibit a marked latitudinal variability in terms of mean precipitation. In particular, increased mean is observed in the northern regions compared with the central Peru regions, which is consistent with the larger oceanic influence on precipitation. Such meridional anisotropy is also found for the relationship between precipitation and ENSO consistent with previous studies (Lagos et al., 2008; Lavado et al., 2013). It is here shown that the strong positive relationship between precipitation and ENSO over the entire records results mostly from the influence of the strong events of 1982/1983 and 1997/1998. Without considering these extreme events, the relationship between ENSO and precipitation exhibits a significant decadal modulation with the larger ENSO impact over the 1990s and afterwards. In particular, in the 2000s, the relationship between ENSO variability and precipitation reverses compared with the previous decade, i.e. El Niño occurrence is associated to reduced precipitation. This period is also associated to the occurrence of only $\mathrm{CP} \mathrm{El}$ Niño events that are associated with neutral to cool SST anomalies along the coast of Peru.

A variety of ENSO indices, including the $\mathrm{C}$ and $\mathrm{E}$ indices recently defined by Takahashi et al. (2011), are used to estimate trends in the ENSO-precipitation relationship. We also use indices derived from equatorial oceanic Kelvin wave estimates in order to take into account oceanic influences not directly related to the interannual variability over the entire tropical Pacific. Oceanic Kelvin wave at intraseasonal timescales can in particular impact SST along the coast and modify the mixing in the marine boundary layer along the coast leading to either increased convection (mostly in the northern part of Peru) or increased stability under upwelling events (all along the coast). Our analysis indicates that in the recent decades, the ENSO influence on precipitation along the coast is characterized by an 
inverse relationship, which results from both the increased occurrence of CP El Niño events that lead to cooler SST conditions off Peru (Dewitte et al., 2012) and from the influence of La Niña events and upwelling events. The mean SST off Peru has cooled in the recent decades (Gutierrez et al., 2011; Dewitte et al., 2012). A shift towards cooler conditions in the 1990s is also observed in the mean state of the tropical Pacific (Hong et al., 2013) that is suggested to be concomitant to the increased occurrence of CP El Niño (Chung and Li, 2013). So, both changes in mean upwelling and in upwelling variability may contribute to strengthen the inverse relationship between ENSO and precipitation along the coast of Peru over the recent decades.

Overall, our results suggest a significant change in the ENSO-precipitation relationship along the coast of Peru due to the predominance of CP El Niño type in recent decades. It calls for better understanding the oceanic influence on the marine boundary layer considering cooler SST along the coast tends to stabilize the marine boundary layer and lead to drier conditions near-shore. On the other hand, most of the regions considered here are located at a $2000 \mathrm{~m}$ elevation, which is above the marine boundary layer, so that precipitation changes may be influenced by non-local processes. A better understanding of the regional atmospheric circulation in this region is required, which will help in better identifying key indices that can be related to precipitation variability at different altitude along the coast. This can be addressed from the experimentation with a regional high-resolution atmospheric model, which is planned for future work.

In the same way, the use of the ten ENSO indices associated with different facets of ENSO (ENSO canonical vs ENSO Modoki) improves our understanding of the complex relationship between precipitation and ENSO in Peru (from northern to centre of Pacific coast). We plan to extend this type of studies at regional scale to help improve climate and hydrological forecasts for the most affected countries of the Pacific coast of South America (Peru and Ecuador).

\section{ACKNOWLEDGEMENTS}

We thank Prof. Dacha Gushchina (University of Moscow) for carrying the MJO index calculation from NCEP/NCAR reanalysis. The three anonymous reviewers are thanked for their constructive comments.

\section{REFERENCES}

An S-I, Jin F-F. 2004. Nonlinearity and asymmetry of ENSO. Journal of Climate 17: 2399-2412.

Ashok K, Behera SK, Rao SA, Weng H, Yamagata T. 2007. El Niño Modoki and its possible teleconnection. Journal of Geophysical Research 112: C11007.
Bograd SJ, Schroeder I, Sarkar N, Qiu X, Sydeman WJ, Schwing FB 2009. The phenology of coastal upwelling in the California Current. Geophysical Research Letters 36: L01602. DOI: 10.1029/2008GL035933.

Boucharel J, Dewitte B, Garel B, duPenhoat Y. 2009. ENSO's nonstationary and non-Gaussian character: the role of climate shifts. Nonlinear Processes in Geophysics 16: 453-473.

Bourrel L, Labat D, Vera A, Coutaud A, Ronchail J, Guyot JL, Armijos E, Pombosa R. 2010. Correlation between the climatic indices of the ENSO phenomenon (El Niño - La Niña) and the rains and discharges indices on the Pacific coast of South America: Esmeraldas river basin, International Workshop on ENSO, Decadal Variability and CC in South America, October $12^{-}$14, 2010: Guayaquil, Ecuador.

Bourrel L, Melo P, Vera A, Pombosa R, Guyot JL. 2011. Study of the erosion risks of the Ecuadorian Pacific coast under the influence of ENSO phenomenon: case of the Esmeraldas and Guayas basins, World's Large Rivers Conference 2011, International Conference on the Status and Future of the World's Large Rivers. April 11 - 14, 2011 : Vienna, Austria.

Brunet-Moret Y. 1979. Homogénéisation des précipitations. Cahiers ORSTOM, sér. Hydro-biologie XVI(3-4): 147-170.

Chung P-H, Li T. 2013. Interdecadal relationship between the state and El Niño types. Journal of Climate 26(2): 361-379.

Dewitte B, Purca S, Illig SL, Renault L, Giese B. 2008. Low frequency modulation of the intraseasonal equatorial Kelvin wave activity in the Pacific Ocean from SODA: 1958-2008. Journal of Climate 21: 6060-6069.

Dewitte B, Illig S, Renault L, Goubanova K, Takahashi K, Gushchina D, Mosquera K, Purca S. 2011a. Modes of covariability between sea surface temperature and wind stress intraseasonal anomalies along the coast of Peru from satellite observations (2000-2008). Journal of Geophysical Research 116: C04028. DOI: 10.1029/2010JC006495.

Dewitte B, Choi J, An S-I, Thual S. 2011b. Vertical structure variability and equatorial waves during Central Pacific and Eastern Pacific El Niño in a coupled general circulation model. Climate Dynamics DOI: 10.1007/s00382-011-1215-x.

Dewitte B, Vazquez-Cuervo J, Goubanova K, Illig S, Takahashi K, Cambon G, Purca S, Correa D, Gutierrez D, Sifeddine A, Ortlieb L. 2012. Change in El Niño flavours over 1958-2008: implications for the long-term trend of the upwelling off Peru. Deep Sea Research II. DOI: 10.1016/j.dsr2.2012.04.011.

Diaz H, Markgraf V. 2000. El Niño and the southern oscillation: multiscale variability and global and regional impacts. Cambridge University Press: Cambridge; 496.

Gottschalck J, Higgins W. 2008. Madden Julian oscillation impacts. NOAA/NWS/NCEP Climate Prediction Center.

Guilderson TP, Schrag DP. 1998. Abrupt shift in subsurface temperatures in the tropical Pacific associated with changes in El Niño. Science 281: 240-243.

Gutiérrez D, Bertrand A, Wosnitz-Mendo C, Dewitte B, Purca S, Peña C, Chaigneau A, Tam J, Graco M, Echevin V, Grados C, Fréon P, Guevara-Carrasco R. 2011. Sensibilidad del sistema de afloramiento costero del Perú al cambio climático e implicancias ecológicas. RPGA SENAMHI 3: 1-24.

Gushchina D, Dewitte B. 2012. Intraseasonal tropical atmospheric variability associated to the two flavors of El Niño. Monthly Weather Review 140(11): 3669-3681.

Hayashi Y. 1982. Space-time spectral analysis and its applications to atmospheric waves. Journal of the Meteorological Society of Japan 60 : $156-171$.

Heil C, Walnut D. 1989. Continuous and discrete wavelet transforms. SIAM Review 31: 628-666.

Hendon HH, Wheeler MC, Zhang C. 2007. Seasonal dependence of the MJO-ENSO relationship. Journal of Climate 20: 531-543.

Hong C-C, Wu Y-K, Li T, Chang C-C 2013. The climate regime shift over the Pacific during 1996/1997. Climate Dynamics. DOI: 10.1007/ s00382-013-1867-9.

Kiem A, Franks S. 2001. On the identification of ENSO-induced rainfall and runoff variability: a comparison of methods and indices. Hydrological Sciences 46(5): 715-727.

Kim ST, Yu J-Y 2012. The two types of ENSO in CMIP5 models. Geophysical Research Letters 39: L11704. DOI: 10.1029/2012GL052006.

Kug JS, Jin F-F, An S-I 2009. Two types of El Niño events: cold tongue El Niño and warm pool El Niño. Journal of Climate 22: 1499-1515. 


\section{TREND AND MODULATION OF ENSO/PRECIPITATION RELATION (PERUVIAN COAST)}

Labat D, Ababou R, Mangin A. 2000. Rainfall-runoff relations for karstic springs. Part II: continuous wavelet and discrete orthogonal multiresolution analyses. Journal of Hydrology 238(3): 149-178.

Labat D. 2005. Recent advances in wavelet analyses: part 1. A review of concepts. Journal of Hydrology 314-1: 275-288.

Labat D. 2006. Oscillations in land surface hydrological cycle. Earth and Planetary Science Letters 242(1): 143-154.

Lagarde J. 1983. Initiation à l'analyse des données, BORDAS (eds)., Paris, $157 \mathrm{p}$.

Lagos P, Buizer J. 1992. El Niño and Peru interannual climate variability, Natural and Technological Disasters. Chapter 17. The Pennsylvania Academy of Science.

Lagos P, Silva Y, Nickl E, Mosquera K. 2008. El Niño - related precipitation variability in Peru. Advances in Geosciences 14: 231-237.

Lavado W, Silvestre E, Felipe O, Bourrel L. 2013. ENSO impact on hydrology in Peru, Advances in Geosciences 11: 1-7.

Lee T, McPhaden M. 2010. Increasing intensity of El Nino in the central equatorial Pacific. Geophysical Research Letters 37: L14603. DOI: 10.1029/2010GL044007.

Luo JJ, Sasaki W, Masumoto Y. 2012. Indian Ocean warming modulates Pacific climate change. Proceedings of the National Academy of Sciences of the United States of America 109: 18701-18706.

Madden R, Julian P. 1972. Description of global-scale circulation cells in the tropics with a 40-50 day period. Journal of the Atmospheric Sciences 29: 1109-1123.

McPhaden MJ, Zhang X, Hendon HH, Wheeler MC 2006. Large scale dynamics and MJO forcing of ENSO variability. Geophysical Research Letters 33(16): L16702. DOI: 10.1029/2006GL026786.

McPhaden MJ. 2012. A 21st century shift in the relationship between ENSO SST and warm water volume anomalies. Geophysical Research Letters 39: L09706. DOI: 10.1029/2012GL051826.

Miller A, Cayan D, Barnett T, Graham N, Oberhuber J. 1994. The 1976-77 climate shift of the Pacific Ocean. Oceanography 7: 21-26.

Montecinos, A, P Aceituno, 2003. Seasonality of the ENSO-related rainfall variability in central Chile and associated circulation anomalies. Journal of Climate 16: 281-296.

Mosquera K, Dewitte B, Illig S, Takahashi K, Garric G. 2013. The 2002/ 03 El Niño: equatorial wave sequence and their impact on sea surface temperature. Journal of Geophysical Research: Oceans 118: 1-12.

OPS. 2000. Perú: Fenómeno El Niño, 1997-1998. Organización Panamericana de la Salud. Fenómeno El Niño, 1997-1998, Washigton D.C.
Rasmusson E, Carpenter T. 1982. Variations in tropical sea surface temperatures and wind fields associated with the southern oscillation/El Nino. Monthly Weather Review 110: 354-384.

Roundy PE, Kiladis GN 2006. Observed relationship between oceanic Kelvin waves and atmospheric forcing. Journal of Climate 19: 5253-5272.

Takahashi K, Montecinos A, Goubanova K, Dewitte B. 2011. ENSO regimes: reinterpreting the canonical and Modoki Niño. Geophysical Research Letters 38: L10704.

Tapley T, Waylen P. 1990. Spatial variability of annual precipitation and ENSO events in western Peru. Hydrological Sciences Journal 35: 4, 429-446.

Torrence C, Compo G. 1998. A practical guide to wavelet analysis. The Bulletin of the American Meteorological Society 79: 61-78.

Torrence C, Webster PJ. 1999. Interdecadal changes in the ENSO-monsoon system. Journal of Climate 12: 2679-2690.

Tsonis A, Swanson K, Kravtsov S. 2007. A new dynamical mechanism for major climate shifts. Geophysical Research Letters 34: 113705.

Vecchi GA, Harrison DE 2000. Tropical Pacific sea surface temperature anomalies, El Niño and equatorial westerly wind events. Journal of Climate 13(11): 1814-1830.

von Storch H, Zwiers F, 2003. Statistical Analysis in Climate Research. Cambridge University Press: Cambridge; 495.

Waliser DE, Lau KM, Stern W, Jones C 2003. Potential predictability of the Madden-Julian Oscillation. Bulletin of the American Meteorological Society 84: $33-50$.

Waliser DE 2005. Predictability and forecasting. In Intraseasonal Variability of the Atmosphere-Ocean Climate System, Lau WKM, Waliser DE (eds). Springer Heidelberg: Germany.

Wheeler M, Kiladis G. 1999. Convectively coupled equatorial waves. Analysis of clouds and temperature in the wavenumber-frequency domain. Journal of the Atmospheric Sciences 56: 374-399.

Wheeler M, Weickmann KM. 2001. Real-time monitoring and prediction of modes of coherent synoptic to intraseasonal tropical variability. Monthly Weather Review 129: 2677-2694.

Woodman R. 1985. Recurrencia del Fenómeno El Niño con intensidad comparable a la del Niño 1982-1983. Concejo Nacional de Ciencia y Tecnología (CONCYTEC), Lima; 301-332.

Xiang B, Wang B, Li T. 2012. A new paradigm for the predominance of standing Central Pacific Warming after the late 1990s. Climate Dynamics. DOI: 10.1007/s00382-012-1427-8.

Yeh SW, Kug SJ, Dewitte B, Kwon M, Kirtman B, Jin F 2009. El Niño in a changing climate. Nature 461: 511-514. 